\title{
SENTIDOS SOCIAIS PARA A EDUCAÇÃO BRASILEIRA A PARTIR DO PENSAMENTO DECOLONIAL
}

\section{SOCIAL MEANINGS OF BRAZILIAN EDUCATION UNDER A DECOLONIAL PERSPECTIVE}

\author{
Adriana Santiago Rosa Dantas \\ Pós-doutoranda em Educação, Universidade Estadual de Campinas - Unicamp \\ Campinas, São Paulo - Brasil \\ novadrica@gmail.com
}

\begin{abstract}
Resumo: Este artigo visa discutir os sentidos sociais da educação formal na perspectiva decolonial a partir do conceito de colonialidade do poder, propondo uma atualização do conceito para o contexto brasileiro. Isso implica pensar a educação brasileira considerando as questões raciais como estruturantes das desigualdades sociais desde o tempo da Colônia. A colonização luso-hispânica, que foi caracterizada pela exploração e genocídio dos povos nativos, pela expropriação de suas terras e pelo sequestro de africanos para o trabalho escravizado nas terras então apropriadas, pode ser considerada o principal exemplo de marca distintiva a diferenciar os sentidos sociais da educação latino-americana da europeia. Isso parece ocorrer devido a fatores estruturantes próprios aos quais os diferentes continentes foram submetidos, criando lacunas sobre os sentidos sociais dessa educação, quando analisadas sem as devidas diferenciações. A revisão da literatura foi utilizada como principal metodologia para a discussão do tema proposto, por meio da qual pode-se concluir que, desde o tempo colonial, a separação entre escola privada e escola pública já apontava para um recorte mais profundo das desigualdades sociais, em que as questões econômicas e raciais estavam envolvidas.
\end{abstract}

Palavras-chave: Colonialidade do poder. Educação brasileira. Escola privada. Escola pública. Pensamento decolonial.

Abstract: This article presents the social meanings of formal education under a decolonial perspective based on the concept of coloniality of power, proposing an update to the concept for the Brazilian context. This implies thinking Brazilian education considering the racial issues as structing social inequalities since colonial times. Luso-Hispanic colonization, which was characterized by the exploitation and genocide of native people, the expropriation from their lands, and the kidnapping of Africans for slave work in those lands, can be considered as the main example of the distinctive marks that can distinguish the social meanings of Latin-American education from the European ones. This is due to the specific structuring factors to which different continents were submitted, leading to gaps on the social meanings of education when these are analyzed without considering those differences. We used a literature review methodology to conclude that, since colonial times, the separation between private and public school already pointed to a deeper social inequality, involving economic and racial issues.

Keywords: Coloniality of power. Brazilian education. Private school. Public school. Decolonial thought.

\section{Para citar - (ABNT NBR 6023:2018)}

DANTAS, Adriana Santiago Rosa. Sentidos sociais para a educação brasileira a partir do pensamento decolonial. Eccos - Revista Cientifica, São Paulo, n. 54, p. 1-14, e17319, jul./set. 2020. Disponível em: https://doi.org/10.5585/eccos.n54.17319. 


\section{Introdução ${ }^{1}$}

A centralidade da educação ${ }^{2}$ através da escola teve sua gênese na constituição da Idade Moderna na Europa, período compreendido entre os séculos XVI e XVII, segundo alguns autores. Naquele contexto, o Estado moderno se constituiu e com ele todo aparato ideológico e burocrático que tal constituição demandou. Era o momento da formação de um mercado global, tendo como centro controlador a Europa. Com a consolidação do capitalismo a partir do século XVIII, alguns países europeus impuseram o modo de produção capitalista em uma escala mundial, adotando para si o que seria o modelo do moderno no mundo, hierarquizando países entre "civilizados" e "não civilizados". A ciência realizada naquele continente começa a produzir princípios que passam a ser considerados como universais para legitimar sua posição no topo da hierarquia. E esse novo tipo de conhecimento passa a ser propagado na escola europeia, a partir de sua incorporação no currículo. Assim, esta escola fazia parte do projeto civilizatório da modernidade europeia, pois ela consistia no lócus da pedagogia iluminista, cuja crença na razão humana trazia uma revolução cultural que se separava da centralidade da religião como norteadora da sociedade. Na Europa, isso se traduzia na crença na razão e na ciência moderna como meios de orientar e conduzir o mundo (ARIÈS, 1981; DURKHEIM, 2016; QUIJANO, 2005; SOUZA, 2007).

Muitas vezes, no Brasil, o modelo da escola europeia é tomado para análise do contexto latino-americano sem as devidas atualizações. Dito de outro modo, essa concepção da centralidade da escola precisa ser repensada levando em conta a realidade da América Latina, em uma perspectiva decolonial ${ }^{3}$.

A colonização brasileira - caracterizada pela exploração e genocídio dos povos nativos, pela expropriação de suas terras pelos portugueses e pelo sequestro de africanos para o trabalho escravizado nas terras então apropriadas - pode ser considerada o principal exemplo de marca distintiva a diferenciar os sentidos sociais da educação europeia da educação latino-americana. Isso ocorre devido a fatores estruturantes próprios aos quais os diferentes continentes foram submetidos, criando lacunas sobre os sentidos sociais dessa educação. Uma das consequências é a falta da articulação da questão racial, decorrente da escravização ocorrida, para compreender a estrutura social brasileira e como isso se relaciona os sentidos da educação nacional.

\footnotetext{
${ }^{1}$ Agradeço a leitura prévia de Gabriela Valente e Flávia Fávari.

${ }^{2}$ Concorda-se que educação é mais ampla e não se reduz ao estabelecimento escolar. Todavia, este artigo tratará da educação formal realizada na escola, por isso, serão utilizados como sinônimos os termos educação, educação formal ou escola.

${ }^{3}$ A síntese do movimento do giro decolonial, liderado por autores latino-americanos como Anibal Quijano, Walter Mignolo, Enrique Dussel dentre outros, pode ser vista em Ballestrin (2013)
} 
No século XX ficaram evidenciadas as consequências da escravidão na estrutura social do Brasil pelos estudos que trouxeram à baila a questão racial. O racismo estrutural, conforme Hasenbalg (2005), exerceu uma funcionalidade na estratificação social, resultando em privilégios aos brancos com acesso a bens materiais e simbólicos na estrutura social em detrimento das vantagens aos não brancos. Nessa contradição social, a educação cumpria um papel importante para reprodução ou mobilidade social, que estavam profundamente relacionadas às desigualdades raciais no Brasil (HASENBALG; SILVA; LIMA, 1999). O cenário na primeira década do século XXI confirmou a persistência das desigualdades educacionais no que diz respeito à questão racial, pois os negros continuaram nas posições menos privilegiadas (GARCIA, 2007; LIMA; PRATES, 2015).

Assim, perguntas foram suscitadas: se essas desvantagens são cumulativas, transmitidas de geração a geração, qual a relação entre o sistema escravista e a educação brasileira? Se o racismo é estrutural, quais os sentidos da educação formal nesta conjuntura? Em outras palavras, como opera a escola como propagadora do racismo pela via institucional?

Como resposta ao desafio de compreensão desse quadro, entendeu-se como necessidade teórica aprofundar a questão racial, como um fator decisivo e negligenciado, a partir da epistemologia decolonial, pois como afirma Ballestrin (2013, p. 108) “[...] aquilo que é original dos estudos decoloniais parece estar mais relacionado com as novas lentes colocadas sobre velhos problemas latino-americanos do que com o elenco desses problemas em si”. Este artigo, portanto, visa discutir outros sentidos sociais para a educação brasileira a partir dessas condições estruturantes que podem ser sintetizadas pela experiência da colonização brasileira, a qual forjou um tipo de educação formal que estava alinhada a tal estrutura social e que não pode ser pensada nos mesmos parâmetros do ideário educacional da Europa. Apesar da distância histórica do evento, assume-se que nele seria possível encontrar chaves teóricas para as relações educacionais, sendo necessário tal resgate analítico. O intuito é montar uma espinha dorsal desta estrutura social, cuja centralidade das relações raciais ainda está obscurecida, para, então, alocar outros sentidos sociais da educação na proposta esquemática apresentada no Quadro 1.

Tal esforço teórico foi realizado na tese de Dantas $(2018)^{4}$. Aquela discussão está sendo refeita neste momento com novas abordagens. $\mathrm{O}$ autor de pensamento decolonial utilizado para a empreitada foi o sociólogo peruano Aníbal Quijano. O conceito de colonialidade do poder foi

\footnotetext{
${ }^{4}$ Pesquisa realizada sob a orientação da profa. Dra. Maria da Graça Setton, na Faculdade de Educação da Universidade de São Paulo, com o financiamento da Capes/ Fapesp (Processo 2015/05846-0). As conclusões expressas neste artigo são de responsabilidade da autora e não refletem necessariamente a visão da FAPESP e da CAPES.
} 
utilizado para instrumentalizar a questão racial na estrutura social brasileira e debater sentidos sociais para a educação formal.

O artigo está dividido em quatro partes, além desta introdução. Em primeiro lugar, será apresentado o conceito de colonialidade do poder. Em seguida, será debatido como este conceito foi trabalhado segundo as especificidades brasileiras. À luz deste arcabouço teórico, serão discutidos alguns sentidos sociais da educação formal brasileira. Por fim, serão tecidas as considerações finais.

\section{A colonialidade do poder}

O conceito de colonialidade do poder, cunhado por Quijano (1992; 2005; 2009), é compreendido como um padrão de dominação que foi forjado durante a constituição do que viria a ser a América Latina a partir do século XVI. De forma geral, tal padrão sustentou-se em dois eixos. O primeiro diz respeito à criação de novas identidades de acordo com a raça (indígenas, negros, mestiços, brancos) para legitimar a divisão do trabalho (servil, forçado, assalariado). O segundo tem a ver com a concepção de mundo europeia, o eurocentrismo. A colonialidade está vinculada ao colonialismo; contudo, este se constitui em estrutura de dominação de um povo sobre outro, mais antiga que a colonialidade, mas que não necessariamente se compõe por relações raciais de poder (QUIJANO, 2009). Sobre a dominação por raça, diz o autor:

Colonialidade do poder é um conceito que dá conta de um dos elementos fundantes do atual padrão de poder, a classificação social básica e universal da população do planeta em torno da ideia de "raça". Essa ideia e a classificação social e baseada nela (ou "racista") foram originadas há 500 anos junto com América, Europa e o capitalismo. São a mais profunda e perdurável expressão da dominação colonial e foram impostas sobre toda a população do planeta no curso da expansão do colonialismo europeu. Desde então, no atual padrão mundial de poder, impregnam todas e cada uma das áreas de existência social e constituem a mais profunda e eficaz forma de dominação social, material e intersubjetiva, e são, por isso mesmo, a base intersubjetiva mais universal de dominação política dentro do atual padrão de poder. (QUIJANO, 2002, p.4)

Assim, a "criação" de novas identidades hierarquizou o europeu - branco - como o "civilizado" contrapondo-se ao "outro não civilizado". A colonialidade do poder aponta que este padrão racial global foi se estabelecendo de maneira tão profunda que perdura até os dias atuais. A raça como categoria mental da modernidade foi construída no colonialismo para naturalizar a dominação de um povo sobre o outro, o que leva ao segundo eixo, a divisão do trabalho por raça.

O segundo eixo refere-se ao controle e à exploração do trabalho e dos recursos das colônias, assim como o controle da "produção-apropriação-distribuição dos produtos" 
subordinados ao capital e a um mercado mundial. As relações estabelecidas tinham como objetivo a produção para esse mercado. Foi naquela fase que se estabeleceu, pela primeira vez, um padrão global que caracteriza o capitalismo mundial, outorgando à Europa o centro desse sistema. A crença de inferioridade racial dos nativos e, mais tarde, dos africanos escravizados, foi naturalizando a percepção dos brancos de que o salário era um privilégio destes. Realizouse a associação de que o trabalho não pago ou servil se destinava às "outras" identidades não europeias. A expropriação das terras dos nativos e a apropriação dos produtos das colônias também se justificavam por esse motivo.

A colonialidade de poder forjou-se desde o século XVI como um padrão mundial de controle das relações sociais, das relações de gênero, do controle do trabalho por instituições como a família, a empresa capitalista e o Estado (após colonização). Por isso, o autor defende uma nova abordagem para a classificação social que abarque a complexidade das relações para além das classes sociais marxistas do contexto fabril, pois é necessário considerar os seguintes aspectos, como os da América Latina:

1) A coexistência e a associação, sob o capitalismo, de todas as formas de exploração/dominação do trabalho; 2) que, consequentemente, mesmo reduzindo as classes sociais apenas às relações de exploração/dominação em torno do trabalho, no mundo do capitalismo não existiam somente as classes sociais de 'industriais', de um lado, e a de 'operários' ou 'proletários' do outro, mas também a de 'escravos', 'servos' e 'plebeus', 'camponeses livres'; 3) sobre o facto de que as relações de dominação originadas na experiência colonial de 'europeus' ou 'brancos' e 'índios', 'negros', 'amarelos' e 'mestiços', implicavam profundas relações de poder que naquele período, por estarem tão estreitamente ligadas às formas de exploração do trabalho, pareciam 'naturalmente' associadas entre si; 4) que em consequência, a relação capital-salário não era o único eixo do poder, nem sequer na economia; 5) que havia outros eixos do poder que existiam e actuavam em meios que não eram somente económicos, como a 'raça', o género e a idade; 6) que, consequentemente, a distribuição de poder entre a população de uma sociedade não provinha exclusivamente das relações em torno do controlo do trabalho, nem se reduzia a elas. (QUIJANO, 2009, p. 92)

A análise de Quijano permite pensar que coexistem, nas relações de poder, a exploração e dominação (raça/gênero), as quais precisam ser articuladas. Inspirando-se nesta proposição, realizou-se a tentativa de discutir tal especificidade para o contexto brasileiro.

\section{A colonialidade do poder à brasileira}

Este artigo, inspirado na classificação social de Quijano (2009), visa apresentar uma proposta de espinha dorsal da colonialidade do poder à brasileira no período colonial, para compreender como foi se forjando uma estrutura social racista, e assim discutir possíveis sentidos sociais da educação formal em tal estrutura. Para tanto, é preciso compreender que a Colônia se constituiu tendo como base econômica o trabalho agrícola em terras apropriadas de 
nativos que foram obrigados a trabalhar por Portugal. A posse da terra foi a primeira separação de base econômica que dividiu os europeus colonizadores dos nativos expropriados. Mais tarde, com a chegada forçada dos africanos, o trabalho agrícola, por meio da escravidão que enriqueceu os donos das terras, foi realizado por diversos povos daquele continente, tendo a raça como justificativa para a exploração.

A colonialidade do poder dá a base teórica para identificar que a questão racial na América Latina foi estruturante das relações sociais, ao demonstrar que o trabalho produtivo e a classificação social tinham a raça como fundamento. Quijano defende que não houve apenas a exploração do trabalho, mas também relações de dominação de gênero e raça, que acabaram por naturalizar a exploração/dominação como o mesmo componente. Assim, defende-se que a questão racial não é um tema identitário no Brasil, mas se constitui em um fator estruturante nas relações sociais.

Por isso, neste artigo tentou-se esmiuçar as dominações de gênero e raça para propor a colonialidade do poder à brasileira. Assim, foi possível intuir que pobre branco e pobre negro poderiam ter status diferentes na sociedade, especialmente no acesso à educação. Estendendose à questão de gênero, permite-se distinguir a diferença entre a mulher branca e a mulher negra, pois esta última era destinada ao trabalho doméstico e agrícola na colônia, enquanto isto não era prerrogativa da mulher branca.

Todavia, nessa construção, está posta uma postura epistemológica heterodoxa do conceito de Quijano, defendida na tese de Dantas (2018). Há um caráter simbólico que se manifesta por um conjunto de crenças que pode ser entendido como a relação que há entre os pares, mediada pela autoridade ou crédito que cada um desses agentes tem dentro do seu campo de atuação, cujos capitais simbólicos (culturais, sociais, políticos) também atuam na sociedade (BOURDIEU, 2010). Nesse ponto, a educação fornece as ferramentas necessárias para legitimar ou não posições sociais. O poder simbólico, proposto por Bourdieu, tem papel estratégico e crucial nas estruturas de dominação, e admitir seus mecanismos permite reconhecer como se dá a manutenção das desigualdades e dos privilégios, considerando que a escola é um lócus onde pode se realizar tal manutenção. Assim, para chegar à síntese da colonialidade do poder à brasileira, propõe-se uma ampliação do entendimento do padrão de poder colonial, levando em conta o lado material e o lado simbólico, para refletir sobre o papel da educação em tal conjuntura 5 .

\footnotetext{
${ }^{5}$ Outra crítica em defesa dessa abordagem é a separação por disciplinas na proposta eurocêntrica de fazer ciência que interdita esse tipo de convergência, consistindo tal heterodoxia em uma tentativa de "descolonizar o saber". E como argumentou Ballestrin (2013, p. 109): "Se toda teoria serve para algo ou para alguém, é razoável partir do princípio de que ela reproduz relações de colonialidade do próprio poder.”
} 
Para as especificidades brasileiras que se constituíram a partir de uma colonização portuguesa, diferentemente dos outros países latino-americanos, foi utilizada como metodologia o cotejamento de dois polímatas brasileiros: o pernambucano Gilberto Freyre ${ }^{6}$ e o piauiense Clovis Moura ${ }^{7}$. Tal escolha foi realizada a fim de melhor compreender esse padrão de poder no Brasil pelo qual a raça estrutura a divisão do trabalho, bem como as possíveis interrelações das instituições família e empresa capitalista (que na Colônia parecem coincidir como uma só), e a formação do Estado, para discutir o papel da educação neste paradigma.

Os dois autores estão em posições interpretativas diferentes. Freyre pode ser considerado como o precursor da "ideologia das elites dominantes no Brasil”, e que preserva a ideia de escravidão branda e da "ideia de índole pacífica do povo brasileiro", na perspectiva de Octávio Ianni (2004, p. 13). Por sua vez, para este autor, Clovis Moura foi um dos pioneiros ao analisar a questão social do negro e suas rebeliões de um ponto de vista diferente do da história consolidada, constituindo um dos principais autores que fez uma análise tensional do mito da democracia racial.

De um lado, o uso de Freyre se justifica pela consulta à sua obra em busca do tipo de trabalho que brancos, pretos e mestiços ${ }^{8}$ realizaram no sistema escravista. Evidentemente, foi realizada uma leitura crítica da obra. Tende-se a concordar com Fernando Henrique Cardoso (2006), quando este diz que o livro Casa-grande e senzala é uma obra perene e que continua sendo lida no novo milênio, apesar das críticas a este livro pelo seu conservadorismo, sua falta de apreço ao rigor científico, dentre outras. Segundo este autor, sua permanência se deve ao fato de que a obra de Freyre é resultado de muita pesquisa, tornando-se ainda uma referência para o entendimento do Brasil, pela boa etnografia realizada. Este trabalho específico construiu um mito nacional, a formação do brasileiro como resultante da miscigenação.

Por outro lado, a leitura de Moura se justifica por ele apresentar a tese do conflito social no qual o negro é protagonista e agente promotor do desgaste do sistema escravista (MOURA, 1986; 1992; 1988). O piauiense defende que esse ponto do embate foi sendo subestimado nas ciências humanas, sendo ele salutar para compreender a complexidade da relação entre negros e brancos, pois "O que caracteriza esse período da nossa história social é a luta do escravo contra esse aparelho do Estado" (MOURA, 1988, p.22). O autor cunha o conceito de quilombagem que consiste em uma "[...] uma constelação de movimentos de protesto do

\footnotetext{
${ }^{6}$ Foram consultados os livros Casa-Grande e Senzala: formação da família brasileira sob o regime da economia patriarcal, a $49^{\circ}$ edição de 2004 e a 51º edição de 2006; Novo Mundo nos Trópicos de 1971 e Vida Social no Brasil meados do século XIX, a $4^{\text {a }}$ edição de 2008.

${ }^{7}$ As obras utilizadas foram História do Negro Brasileiro, a $2^{\text {a }}$ edição de 1992; Os quilombos e a rebelião negra, a ${ }^{\text {a }}$ edição de $1986 ;$ Sociologia do Negro Brasileiro de 1988; a $3^{\text {a }}$ edição do Dicionário da Escravidão Negra no Brasil de 2004.

${ }^{8}$ Essa será a designação utilizada para as pessoas com origens entre brancos, pretos e indígenas de forma indistinta. Na atualidade, seria o equivalente ao pardo na classificação oficial do Brasil.
} 
escravo, tendo como centro organizacional o quilombo, do qual partiam ou para ele convergiam e se aliavam as demais formas de rebeldia" (MOURA, 1992, p.22). A resistência negra causava desgaste econômico, social e psicológico da classe senhorial que tinha medo de algum levante negro, nos moldes do que acontecera no Haiti, cuja independência se deu pela maioria negra organizada. Isto porque no Brasil havia uma população numerosa de não brancos que poderia levar a cabo tal empreitada, devido à minoria branca no poder (MOURA, 1986, p. 96).

Assim, analisando-se pela ótica de Moura, a relação casa-grande e senzala reduz a participação do negro na estrutura social, pois não inclui toda a resistência realizada fora da casa-grande, ou mesmo nela própria. Não era do interesse da classe senhorial divulgar a resistência dos negros que era violenta e fortemente reprimida pelo senhor de escravo e pelo aparato militar e jurídico estatal. A coerção não poderia ser apenas física, mas também simbólica, por isso o autor defende a importância da Igreja Católica como aliada ao “[...] montar um aparelho ideológico capaz de dar aos escravos as razões de por que estavam em cativeiro e, aos senhores, racionalizar a violência do opressor" (MOURA, 1986, p. 96). Pode-se sugerir que a relação branda da casa-grande e senzala de Freyre é parte da dominação simbólica, ou da dominação intersubjetiva à luz da colonialidade do poder, mas que não representava a totalidade das relações. A resistência foi sendo reprimida fisicamente e ocultada ideologicamente para perpetuar o mito das relações pacíficas entre brancos e negros no Brasil, como mecanismo de controle social.

O quadro a seguir sugere um esquema da colonialidade do poder à brasileira a partir da leitura dos dois autores citados acima. Assume-se, neste artigo, a limitação de qualquer esquema como redutor da realidade, contudo admite-se a importância de sua construção para desvelar parte da estrutura social. No campo da Sociologia, é possível defender tal estrutura, sabendo que ela não é estática, por isso passível de transformação pela agência dos atores. $\mathrm{Na}$ historiografia atual, é possível vislumbrar as diferentes manifestações de agência dos negros, mas defende-se que, por mais diversa e complexa que seja, toda agência se realiza em uma estrutura social. Por isso, neste quadro, apesar de todas as suas limitações, buscou-se separar a divisão do trabalho por raça e gênero para discutir o sentido da educação formal nesse esquema, com a certeza de que serão necessárias mais pesquisas para aprimorá-lo. 
Quadro 1 - Divisão trabalho/raça/educação na colônia

\begin{tabular}{|c|c|c|}
\hline Trabalho & Raça & Educação \\
\hline $\begin{array}{l}\text { Postos de comando (juristas, } \\
\text { administradores, políticos etc.) }\end{array}$ & Homem Branco & Educação formal e/ou superior \\
\hline Postos militares & Homem Branco & Educação formal e/ou superior \\
\hline Postos religiosos & Homem Branco & Educação formal e/ou superior \\
\hline $\begin{array}{l}\text { Postos médios (profissionais } \\
\text { liberais) }\end{array}$ & Homem Branco & Educação formal e superior \\
\hline Posto de comando doméstico & Mulher Branca & Educação domiciliar feminina \\
\hline $\begin{array}{l}\text { Postos baixos } \\
\text { vaqueiros, } \\
\text { superintendentes de fazendas, } \\
\text { etc.) }\end{array}$ & Homem Branco/Homem Mestiço & $\begin{array}{l}\text { Ausência ou educação } \\
\text { elementar }\end{array}$ \\
\hline $\begin{array}{l}\text { Postos forçados e não pagos } \\
\text { (domésticos/ urbanos/ agrícolas) }\end{array}$ & $\begin{array}{l}\text { Homem Preto/Mulher Preta } \\
\text { Homem Mestiço/Mulher Mestiça }\end{array}$ & Ausência de educação formal \\
\hline $\begin{array}{l}\text { Postos de resistência. (Trabalhos } \\
\text { comunitários da quilombagem }\end{array}$ & $\begin{array}{l}\text { Homem Preto/Mulher Preta } \\
\text { Homem Mestiço/Mulher Mestiça }\end{array}$ & Ausência de educação formal \\
\hline
\end{tabular}

Fonte: Adaptado de Moura e Freyre. * Mestiços: referente a toda miscigenação entre brancos, indígenas e pretos e complementação. Baseado em Dantas (2018, p. 76).

Em uma sociedade patriarcal, propor a divisão racial por gênero foi um exercício interessante, pois Moura não formulou esta especificidade, porém foi do trabalho de Freyre que se pode extrair possibilidades de formas de trabalho ou as posições sociais da mulher indígena, preta, branca e mestiça. Nessas intersecções, o trabalho e a posição da mulher branca e negra são bem distintos e dignos de nota, pois é possível vislumbrar a posição evidente do homem branco nos postos de poder e sua proeminência na educação superior no período colonial e imperial. Enquanto a mulher branca tinha como posição social o papel de esposa, sendo impedida de ocupar posições de comando como o homem branco, as mulheres negras e mestiças trabalhavam tanto no trabalho doméstico para servir a família branca quanto no trabalho rural na produção agrícola. A partir deste quadro, discutir-se-á alguns sentidos sociais para a educação brasileira, enfatizando-se o papel do ensino superior como o nível mais importante 
no que diz respeito às posições de poder, reconhecendo-se que outras discussões são necessárias, mas não são possíveis neste momento.

\section{Sentidos Sociais da Educação formal a partir da colonialidade do poder à brasileira}

A gênese da educação formal brasileira encontra-se no período colonial e está ligada à Igreja Católica. Os primeiros jesuítas tinham o financiamento estatal da metrópole para serem os precursores ideológicos da legitimação da colonização, não só por meio da religião oficial que estava sendo imposta, como também pela educação, como um dos instrumentos de doutrinação dos nativos. Concomitantemente, com a instalação dos portugueses na Colônia, os filhos dos colonos precisaram ser preparados pelos religiosos para frequentar as universidades europeias, especialmente a Universidade de Coimbra. Mesmo depois da expulsão dos jesuítas e da consolidação da Reforma Pombalina no século XVIII, outras ordens católicas continuaram a oferecer educação para os filhos das elites.

As faculdades brasileiras só foram fundadas no período da monarquia brasileira no século XIX. Como bem percebeu Clóvis Moura, os movimentos de resistência causaram impacto na conjuntura social, fazendo com que o governo e as elites se preocupassem com todo o aparato bélico e jurídico para manter sua posição social. Por isso, pouco se associa a fundação dessas faculdades a este conflito. Contudo, à luz da colonialidade do poder à brasileira, é possível sugerir que as primeiras faculdades criadas - de Direito, Medicina e Engenharia estavam ligadas ao controle social. Dito de outro modo, estavam voltadas para a defesa da nação. Conforme afirma Cunha (2011, p. 154-155): "Foi somente em 1874 que o ensino de Engenharia passou a ser realizado em estabelecimentos não militares e voltado para objetivos não bélicos.”. As faculdades de Direito, de maneira mais direta, eram responsáveis por graduar os bacharéis que participariam das criações das leis, assim como do Judiciário para defender os interesses do grupo dominante branco.

Segundo Freyre, os filhos das elites estudavam em internatos separados por gênero. Enquanto as meninas brancas se preparavam para casar, com um "currículo" especialmente voltado para isso, aprendendo a falar francês, bordar, dançar, tocar instrumentos, os rapazes brancos tinham como meta preparatória as academias de Direito e Medicina. A separação do trabalho entre homens brancos e mulheres brancas se distinguia pela possibilidade de o homem exercer os postos de comando social, destinando à mulher o comando domiciliar, que consistia no domínio de empregados pretos e mestiços de ambos os gêneros que estavam escravizados.

Como era comum os pais brancos escolherem a profissão dos filhos, as estratégias familiares consistiam em espalhar os descendentes em diferentes profissões na área da 
Medicina, do Direito, das Forças Armadas e da Religião. Esta última instância era destinada ao filho mais novo, quando os primeiros já estavam "encaminhados" nas profissões mais relevantes socialmente. Como explica Freyre (2008, p. 100): “A tendência era espalhar os meninos em escolas diferentes, de modo que a família patriarcal pudesse ser representada nas diversas profissões então importantes."

Este tipo de instrução era privada e as escolas públicas eram poucas. A legislação oficial do século XIX proibia o acesso dos negros à educação formal elementar, fato que impedia, na base, a possibilidade de um possível acesso ao nível superior, tendo sua faixa de corte bem distante: na instrução primária consoante à lei n. 1, de 1837, e o decreto n. 15, de 1839, sobre Instrução Primária no Rio de Janeiro $-1837^{9}$ :

Artigo $3^{\circ}$ São proibidos de frequentar as Escolas Públicas:

$1^{\circ}$ Todas as pessoas que padecerem molestias contagiosas.

$2^{\circ}$ Os escravos, e os pretos Africanos, ainda que sejão livres ou libertos.

A lei instruía o funcionamento desse nível de ensino nas províncias. Isso demonstrava a seletividade por raça da educação, que não permitia negros, mesmo os livres ou libertos, de frequentar escolas. Desde o tempo colonial, a educação privada confessional distinguiu as pessoas que tinham acesso às profissões mais importantes pelo recorte econômico e racial.

A escola elementar particular no século XIX foi resultado do escasso investimento financeiro do governo geral. Por meio dela, os herdeiros das elites e classes intermediárias puderam acessar o ensino superior e, consequentemente, os postos na administração pública ou nas profissões liberais mais qualificadas socialmente. Consoante Haidar (2008, p. 151), “O ensino privado, irrestritamente livre ao apagar das luzes dos tempos coloniais, permaneceu ainda por muito tempo, após a Independência, totalmente desembaraçado de qualquer interferência governamental.”. As poucas vagas da instrução pública agitavam um mercado da educação privada, especialmente no nível elementar e secundário. Portanto, o ensino privado no Brasil nasce liberal para atender ao ensino elementar dos brancos, visto que ele não era do interesse da monarquia, nem para promovê-lo, muito menos para fiscalizá-lo.

Uma problematização levantada por Greive-Veiga (2008) diz respeito à utilização de "escravos" e "negros" como sinônimos, pois houve um aumento significativo de negros livres a partir da segunda metade do século XIX. A autora defende que a escola pública imperial teria sido destinada a eles e aos brancos mais pobres, devido ao alto índice de analfabetismo. Para ela, “A escolarização do povo apresentou-se como uma condição de homogeneização cultural,

\footnotetext{
${ }^{9}$ Lei n. 1, de 1837, e o decreto n. 15, de 1839, sobre Instrução Primária no Rio de Janeiro - 1837. [Disponível em: http://seer.ufrgs.br/asphe/article/view/29135. Acesso em 17 ago. 2018.].
} 
a institucionalização das aulas/cadeiras de instrução pública elementar não teve como alvo os filhos da elite branca" (GREIVE-VEIGA, 2008, p. 6). Assim, o caráter doutrinador tinha como objetivo homogeneizar o povo segundo o entendimento do que seria civilizado.

Isso porque era consenso entre os pensadores da época que a heterogeneidade populacional, no que dizia respeito às diferenças raciais, era o grande problema a ser solucionado, pois os não brancos eram tomados como os "primitivos", os que impediam o progresso do país. Assim, o projeto dos brancos era civilizar os ditos "primitivos". GreiveVeiga (2008, p.5) completa que: “[...] é possível também verificar que a experiência da vivência da discriminação étnica e racial nas salas de aulas possui uma significativa longevidade histórica, não é recente e vem-se acumulando há quase duzentos anos." Outro aspecto defendido pela autora é que teria sido nesse período a associação de escola pública como o lugar da criança pobre, visto que as famílias mais ricas se valiam do ensino em domicílio.

A tabela da "Divisão trabalho/raça/educação na colônia" pode suscitar algumas outras discussões sobre os sentidos sociais da educação. Como, por exemplo, os pretos e mestiços resistiam nesse contexto em relação à educação? Qual a implicação da educação da mulher branca e da ausência dela para as mulheres pretas, assim como os descendentes de ambas? Todavia, não foi possível discutir essas questões pelo escopo deste artigo.

\section{Considerações finais}

Buscou-se, neste trabalho, demonstrar a importância do nível superior na estrutura social, sobretudo para os postos de comando, e como os caminhos de acesso a estes estavam reservados aos herdeiros, homens e brancos. Não se tratava apenas de um recorte econômico, mas também racial. A separação entre escola privada (ou ensino privado domiciliar) e escola pública já apontava para um recorte mais profundo das desigualdades sociais, em que as questões econômicas e raciais estavam envolvidas.

Do ponto de vista simbólico, o acesso às profissões de nível superior legitimava o lugar do homem branco naquela posição, escamoteando a estrutura que o mantinha em tal condição. Legitimava ainda a dominação sobre a mulher branca que não poderia concorrer na mesma posição social masculina. Em uma estrutura social racista, os não brancos, homens e mulheres, classificados de "não civilizados", tinham na dificuldade do acesso à educação formal mais um fundamento de reiteração da hierarquia inferiorizada. Por outro lado, os postos de resistência estavam sendo controlados pela coerção física e legal, cujo controle social era elaborado pelos 
legisladores e governadores brancos. Além disso, a história de resistência era ocultada dos currículos da educação formal.

Viu-se como o papel da educação pública e privada estava profundamente relacionado ao padrão de poder que separava as identidades entre superiores e inferiores, entre brancos e negros, por exemplo. O histórico da educação pública precária é longevo, antes mesmo da Proclamação da República, e não apresentava o mesmo patamar de qualidade do ensino privado, não significando, portanto, concorrência entre os estudantes que tinham como pagar pela educação, o quais eram majoritariamente brancos.

\section{Referências}

ARIÈS, Philippe. História Social da criança e da família. 2a ed. Rio de Janeiro: LTC, 1981.

BALLESTRIN, Luciana. América Latina e o giro decolonial. Revista Brasileira de Ciência Política, Brasília, n. 11, ago. 2013, p. 89-117.

BOURDIEU, Pierre. O poder simbólico. 14ª . ed. Rio de Janeiro: Bertrand Brasil, 2010.

CARDOSO, Fernando H. Um livro perene. In: FREYRE, Gilberto. Casa-grande e senzala: formação da família brasileira sob o regime da economia patriarcal. 51 ed. São Paulo: Global, 2006. p.19-28.

CUNHA, Luiz Antônio. Ensino Superior e Universidade no Brasil. In: LOPES, Eliane; FARIA FILHO, Luciano; VEIGA, Cynthia. (Orgs). 500 anos de educação no Brasil. $5^{\mathrm{a}}$ ed. Belo Horizonte: Autêntica, 2011, pp 151-204.

DANTAS, Adriana Santiago Rosa. As escolas privadas da periferia de São Paulo: uma análise desde a colonialidade do poder à brasileira. 2018. Tese (Doutorado em Educação) Faculdade de Educação, Universidade de São Paulo, São Paulo, 2018. $213 f$.

DURKHEIM, Émile. Educação e Sociologia. São Paulo: EDIPRO, 2016.

FREYRE, Gilberto. Casa-grande e senzala: formação da família brasileira sob o regime da economia patriarcal. 49 ed. São Paulo: Global, 2004.

FREYRE, Gilberto. Novo Mundo nos Trópicos. São Paulo: Editora Nacional e Editora da USP, 1971

FREYRE, Gilberto. Vida Social no Brasil nos meados do século XIX. $4^{\mathrm{a}}$. ed. revista. São Paulo: Global, 2008.

GARCIA, Renísia C. Identidade Fragmentada: um estudo sobre a história do negro na educação brasileira 1993-2005. Brasília: Instituto Nacional de Estudos e Pesquisas

Educacionais Anísio Teixeira, 2007. 
GREIVE-VEIGA, Cynthia. Escola pública para os negros e os pobres no Brasil: uma invenção imperial. Revista Brasileira de Educação [en linea], vol. 13, n. 39, 2008. Disponível em: http://www.redalyc.org/articulo.oa?id=27503907 Acesso em: 22 ago. 2018.

HAIDAR, Maria de Lourdes M. O ensino secundário no Brasil Império. 2a ${ }^{\text {a }}$ ed. São Paulo: Editora da Universidade de São Paulo, 2008.

HASENBALG, Carlos. Discriminação e desigualdades raciais no Brasil. 2a ${ }^{\text {a }}$ ed. Belo Horizonte: Editora UFMG; Rio de Janeiro: IUPERJ. 2005.

HASENBALG, Carlos; SILVA, Nelson do Valle; LIMA, Márcia. Cor e estratificação social. Rio de Janeiro: Contra Capa Livraria, 1999.

IANNI, Octavio. Octavio Ianni: o preconceito racial no Brasil. Estudos Avançados, v.18, n.50, 2004, p. 6-20.

LIMA, Márcia; PRATES, Ian. Desigualdades raciais no Brasil: um desafio persistente. In: ARRETCHE, Marta. (Org). Trajetórias das desigualdades: como o Brasil mudou nos últimos cinquenta anos. São Paulo: Editora Unesp; CEM, 2015. p. 163-192.

MOURA, Clovis. Dicionário da Escravidão Negra no Brasil. São Paulo: Editora da Universidade de São Paulo, 2004.

MOURA, Clovis. História do Negro Brasileiro. 2a ed. São Paulo: Editora Ática, 1992.

MOURA, Clovis. Os quilombos e a rebelião negra. $6^{\text {a }}$ ed. São Paulo: Editora Brasiliense, 1986.

MOURA, Clovis.Sociologia do Negro Brasileiro. São Paulo: Editora Ática, 1988.

QUIJANO, Aníbal. Colonialidad y modernidad/racionalidad. Perú Indígena, Lima, v. 13, n. 29, 1992. p.11-20.

QUIJANO, Aníbal. Colonialidade, poder, globalização e democracia. Novos Rumos. Ano 17. N. 37, 2002, p. 4-28.

QUIJANO, Aníbal. Colonialidade do poder, eurocentrismo e América Latina. In: LANDER, Edgardo (Org.). A colonialidade do saber: eurocentrismo e ciências sociais. Perspectivas latino-americanas. CLACSO, Ciudad Autónoma de Buenos Aires, Argentina, set. 2005, p.227-278. (Colección Sur). Disponível em:

http://bibliotecavirtual.clacso.org.ar/ar/libros/lander/pt/Quijano.rtf> Acesso em 16 abr. de 2018.

QUIJANO, Aníbal Colonialidade do poder e classificação social. In SANTOS, B.S.; MENEZES, M. P. (org.). Epistemologias do Sul (pp. 73-117). Ciudad Autónoma de Buenos Aires: CLACSO, 2009.

SOUZA, João Valdir. Introdução à Sociologia da Educação. Belo Horizonte: Autêntica, 2007. 